\title{
Corrosion Inhibition Effect of 4-(2-Diethylamino-Ethylsulfonyl)-Phthalonitrile and 4,5-Bis(Hexylsulfonyl)-Phthalonitrile
}

\author{
Esma Sezer, Belkis Ustamehmetoğlu, Zehra Altuntaş Bayır, \\ Kerim Çoban, and Ayfer Kalkan \\ Chemistry Department, Faculty of Science and Letters, Istanbul Technical University, Maslak, 34469 Istanbul, Turkey \\ Correspondence should be addressed to Esma Sezer, esezer@itu.edu.tr
}

Received 1 July 2010; Revised 1 November 2010; Accepted 5 December 2010

Academic Editor: Kenneth I. Ozoemena

Copyright () 2011 Esma Sezer et al. This is an open access article distributed under the Creative Commons Attribution License, which permits unrestricted use, distribution, and reproduction in any medium, provided the original work is properly cited.

\begin{abstract}
Inhibition of stainless steel corrosion in a $3.0 \mathrm{M} \mathrm{NaCl}$ solution by 4-(2-diethylamino-ethylsulfanyl)-phthalonitrile (DAESPN) and 4,5-bis(hexylsulfonyl)-phthalonitrile (Bis-HSPN) was investigated by polarization and electrochemical impedance spectroscopy (EIS) measurements. The values of cathodic $(\beta c)$ and anodic $(\beta a)$ Tafel slopes, $i_{\text {corr }}, E_{\text {corr }}$, corrosion rate $(C R)$, and inhibition efficiences (IE\%) obtained from polarization curves and polarization resistance $\left(R_{\mathrm{P}}\right)$, double-layer capacitance $\left(C_{\mathrm{dl}}\right)$, specific capacitance $\left(C_{\mathrm{sp}}\right)$ values were obtained from EIS. Double-layer capacitance differences in the presence and absence of inhibitors were also obtained from EIS measurements as suggested in the literature in order to investigate the interaction of them with metal surface. Results show that both DAESPN and Bis-HSPN are effective in cathodic reaction. Impedance measurements suggest higher surface coverage for DAESPN. The interaction between the inhibitor and the stainless steel was investigated by the adsorption isotherm. Langmuir adsorption isotherm $K_{\text {ads }}$ was applied and $\Delta G$ values were obtained and found as $4.32 \times 10^{-4}, 1.17 \times 10^{-4}$ and $9.2 \mathrm{~kJ}, 12.5 \mathrm{~kJ}$ for DAESPN and Bis-HSPN, respectively, which suggests the electrostatic interaction between charged metal surface and charged organic molecules.
\end{abstract}

\section{Introduction}

Stainless steel is used in a wide range of industrial applications. Corrosion of steel and its inhibition in chloride solution have attracted the attention of a number of investigators [1-4]. Because of its aggressiveness, inhibitors are used to reduce the rate of dissolution of metals. Compounds containing nitrogen, sulfur, and oxygen are being used for this purpose [5]. The most effective and efficient inhibitors are organic compounds with $\pi$ bonds in their structures. The efficiency of an organic compound as a successful inhibitor is mainly dependent on its ability to be adsorbed on the metal surface, which consists of the replacement of water molecule at a corroding interface. The adsorption of these compounds is influenced by the electronic structure of the inhibiting molecules $[6,7]$ and also by the steric factors, aromaticity, electron density at the donor atoms, and the presence of functional groups [8-13]. EIS is a useful technique to evaluate the effect of sorption of inhibitors on the protection [14]. Double-layer capacitance differences in the presence and absence of inhibitors obtained from EIS measurements can be used in order to investigate the interaction of them with metal surface [15].

Thermodynamic parameters of the corrosion process play an important role to define the spontaneity of the conversion of the metal to corrosion products that can form in the corrosion environments to which the metal is exposed $[16,17]$.

In the present investigation, the corrosion inhibition behaviour of 4-(2-diethylamino-ethylsulfonyl)-phthalonitrile (DAESPN) and 4,5-bis(hexylsulfanyl)-phthalonitrile (Bis-HSPN) on stainless steel in $3.0 \mathrm{M} \mathrm{NaCl}$ solution was investigated using two different techniques: potentiodynamic polarisation curves and electrochemical impedance spectroscopy. The inhibitor efficiency was investigated at different inhibitor concentrations. 

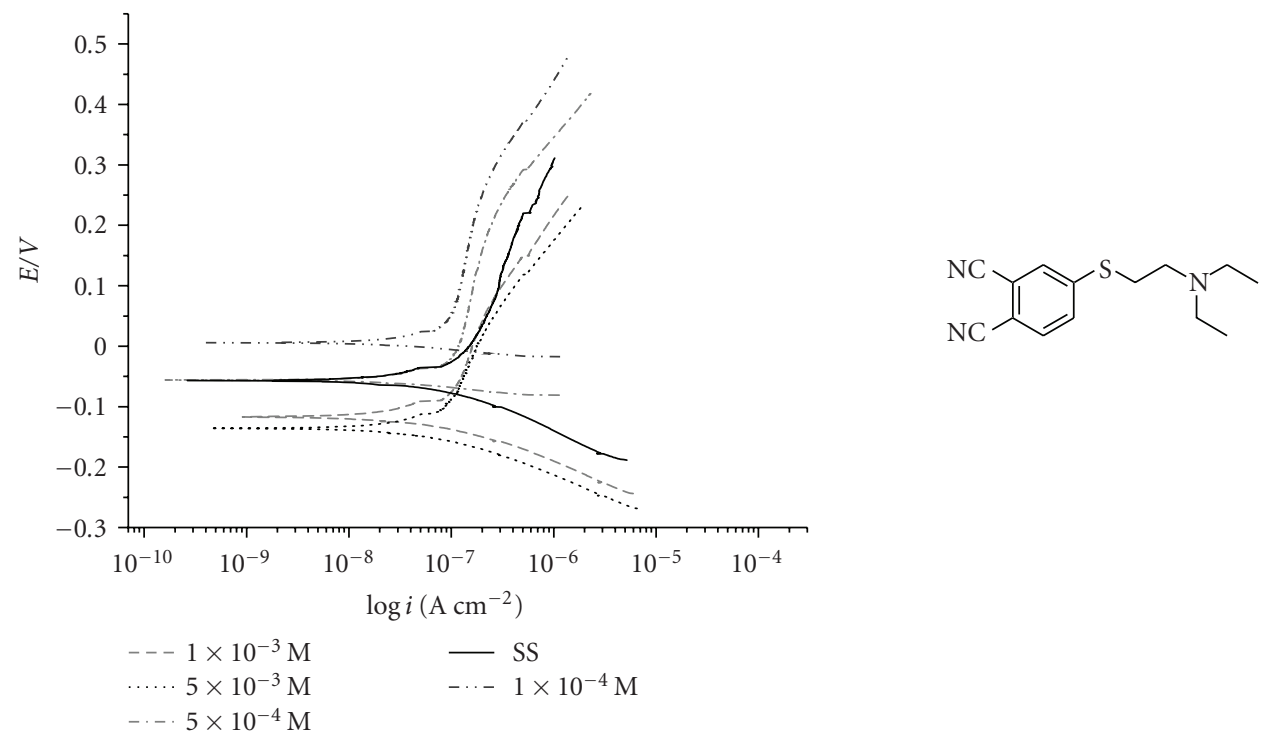

FIGURE 1: Polarization curves of stainless steel in the presence and absence of different concentrations of 4-(2-diethylamino-ethylsulfanyl)phthalonitrile (DAESPN) in $3.0 \mathrm{M} \mathrm{NaCl}$ medium.

TABLE 1: Corrosion values SS in the presence and absence of different concentrations of DAESPN and Bis- $\mathrm{HSPN}$ in $3.0 \mathrm{M} \mathrm{NaCl}$ medium.

\begin{tabular}{|c|c|c|c|c|c|c|c|}
\hline Electrode & Concentration $\mathrm{M}$ & $E_{\text {corr }} \mathrm{mV}$ & $I_{\text {corr }} \mu \mathrm{A}$ & $\beta_{\mathrm{a}}, \mathrm{mV} / \mathrm{dec}$ & $\beta_{\mathrm{c}}, \mathrm{mV} / \mathrm{dec}$ & IE\% & $\mathrm{CR}, \times 10^{3} \mathrm{mmpy}$ \\
\hline Bare & - & -56 & 0.418 & 453.2 & 93.2 & - & 5.0 \\
\hline DAESPN & $1 \times 10^{-3}$ & -116 & 0.273 & 406.5 & 67.9 & 34.6 & 3.3 \\
\hline Bis-HSPN & $1 \times 10^{-3}$ & -4 & 0.171 & 358.9 & 81.4 & 59.0 & 2.1 \\
\hline DAESPN & $5 \times 10^{-3}$ & -135 & 0.253 & 354.0 & 67.8 & 39.4 & 3.1 \\
\hline Bis-HSPN & $5 \times 10^{-3}$ & -75 & 0.381 & 823.4 & 75.2 & 24.0 & 4.6 \\
\hline DAESPN & $5 \times 10^{-4}$ & -55 & 0.305 & 636.7 & 43.8 & 27.0 & 3.7 \\
\hline Bis-HSPN & $5 \times 10^{-4}$ & 40 & 0.226 & 577.2 & 24.8 & 46.0 & 2.7 \\
\hline DAESPN & $1 \times 10^{-4}$ & 6 & 0.278 & 663.4 & 37.7 & 33.4 & 3.3 \\
\hline Bis-HSPN & $1 \times 10^{-4}$ & 18 & 0.293 & 1002.8 & 25.4 & 30.0 & 3.5 \\
\hline
\end{tabular}

\section{Experimental}

The working electrode for electrochemistry measurements was prepared from a cylindrical stainless steel rod (99.99\%) with area of $0.2 \mathrm{~cm}^{2}$. The aggressive environment used was $3.0 \mathrm{M} \mathrm{NaCl}$ solution prepared from analytical reagent-grade chemicals and deionized water. All other chemicals were of AR grade, and the solutions were prepared using deionized water. Electrochemical polarisation curves and electrochemical impedance spectroscopy measurements were performed in a three-electrode cell using a PAR 2263 model potentiostat.

All potential values were reported versus $\mathrm{Ag} / \mathrm{AgCl}$. The working electrode was mechanically polished on wet silicon carbide (SiC) papers $(400,600,1200$ grid), rinsed with deionized water, degreased with acetone and ethanol, and dried at room temperature. It was then polarised $\pm 250 \mathrm{mV}$ from equilibrium potential at $1 \mathrm{mV} / \mathrm{s}$ for electrochemistry polarisation curve tests. The EIS experiments were performed at open circuit potential over a frequency range of $1 \mathrm{MHz}-1 \mathrm{mHz}$, and effect of starting point was also tested in the range of $10 \mathrm{mHz}-10 \mathrm{kHz}$ in order to see if there is any differences in measurements if it is started from low frequency thorough higher frequency and vice versa.The sinusoidal potential perturbation was $10 \mathrm{mV}$ in amplitude. The cell was open to air, and the measurement was conducted at room temperature.

\section{Result and Discussion}

Tafel-extrapolation measurements were done in the potentials region $\pm 250 \mathrm{mV}$ from corrosion potential, $E_{\text {corr }}$. Figures 1 and 2 show typical polarization curves for SS in $3.0 \mathrm{M} \mathrm{NaCl}$ solutions with and without inhibitors of (DAESPN and Bis-HSPN), respectively. The corresponding corrosion potentials $\left(E_{\text {corr }}\right)$, corrosion currents, $\left(i_{\text {corr }}\right)$, anodic Tafel slopes $\left(\beta_{\mathrm{a}}\right)$, and cathodic Tafel slopes $\left(\beta_{\mathrm{c}}\right)$ at different inhibitor concentrations are listed in Table 1.

As it can be seen from Table 1, addition of inhibitor prevents the corrosion up to 60 percent. Inhibitor concentration has only a small effect on inhibition since the corrosion currents do not change significantly by changing concentrations. However increase in concentration shifts the corrosion potential to the more cathodic values. Corrosion rates (CRs) have also calculated as mmpy for practical 


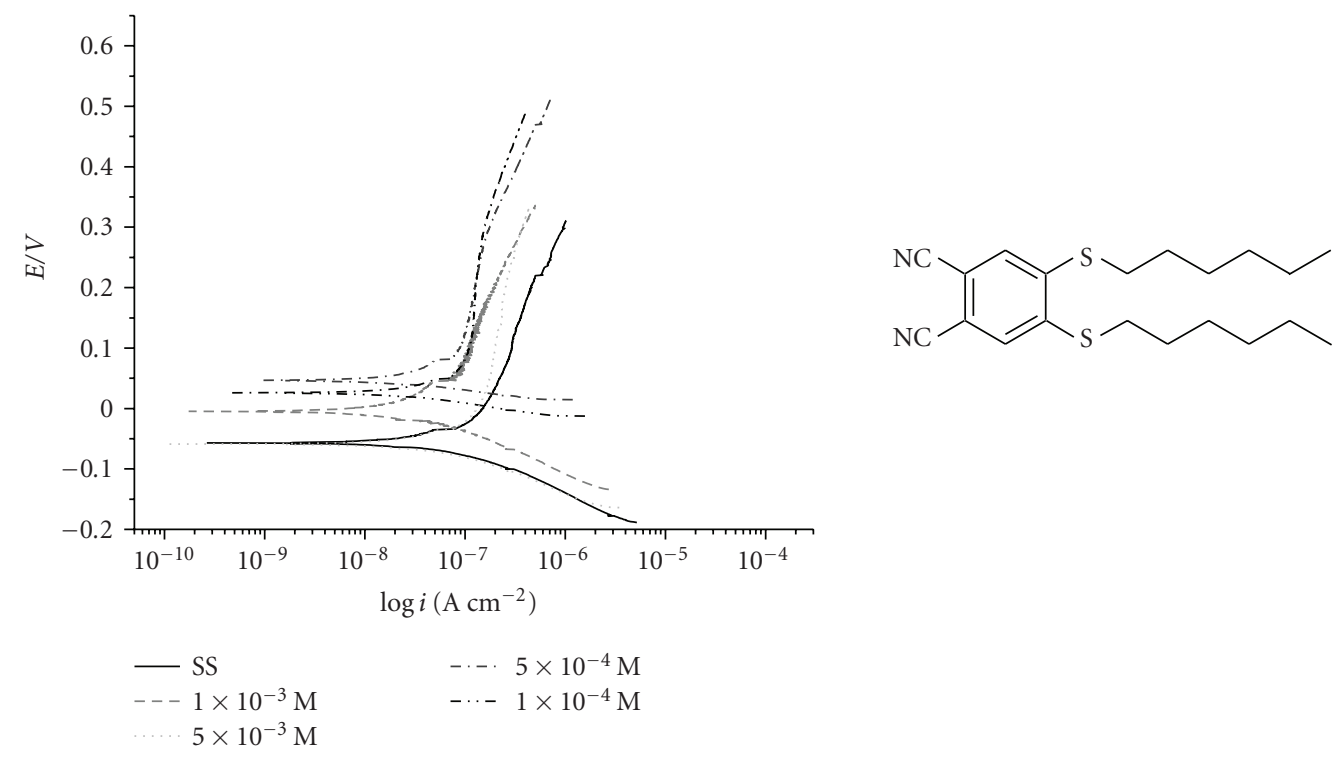

FIGURE 2: Polarization curves of stainless steel in the presence and absence of different concentrations of 4,5-bis(hexylsulfonyl)-phthalonitrile (Bis-HSPN) in $3.0 \mathrm{M} \mathrm{NaCl}$ medium.

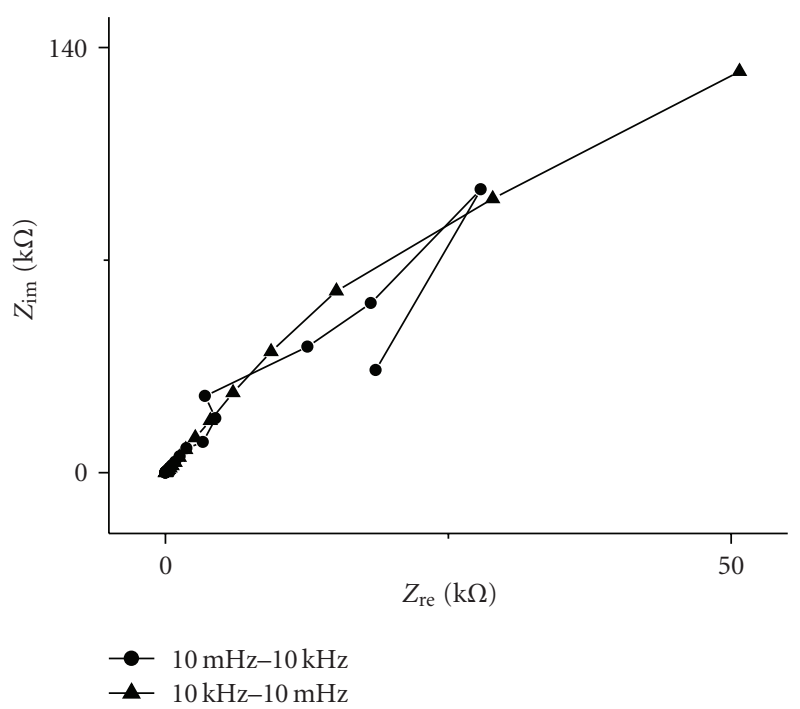

(a)

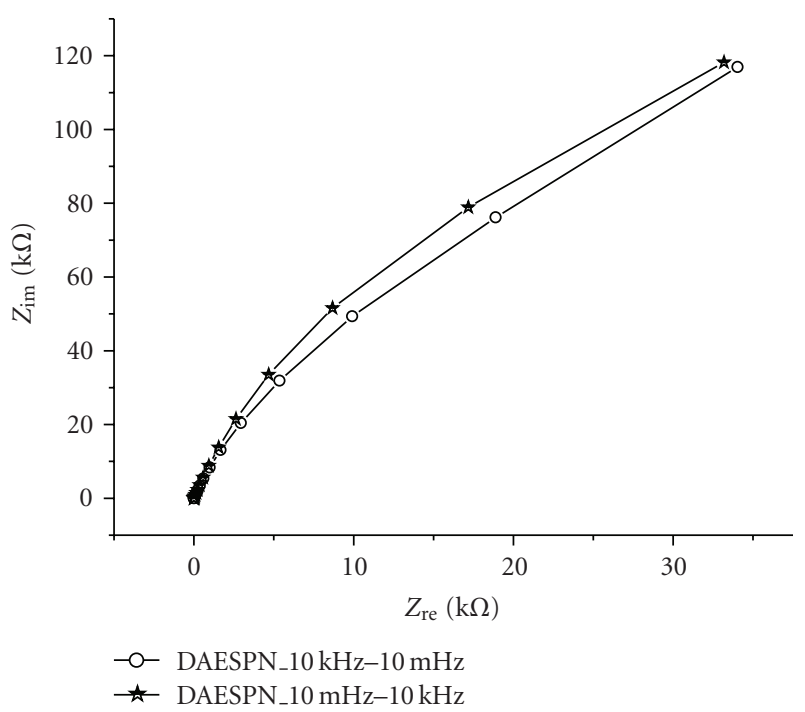

(b)

FIGURE 3: Nyquist plot of SS in the absence and presence of $1 \times 10^{-3} \mathrm{M}$ DAESPN in $3.0 \mathrm{M} \mathrm{NaCl}$ medium.

application, and results show that using $1 \times 10^{-3} \mathrm{M}$ Bis-HSPN produced the lowest corrosion rates for SS.

Impedance spectra of electrodes in the absence and presence of inhibitors were obtained in the frequency range of $1 \mathrm{MHz}-1 \mathrm{mHz}$. Effect of starting point was also tested in the range of $10 \mathrm{mHz}-10 \mathrm{kHz}$. In the first run, impedance spectrum was recorded by starting from low frequency $(10 \mathrm{mHz})$, then frequency was increased up to $10 \mathrm{kHz}$. In the second run measurements were recorded in the reverse direction. Although bare electrode has some deviation when the direction changed (Figure 3(a)), in the presence of DAESPN the electrode becomes more stable that Nyquist plots are almost the same in both direction (Figure 3(b)). This result indicates that presence of inhibitor stabilizes the surface. The frequency in which the phase angle is equal to -45 degrees commonly indicates Warburg diffusion. The absence and presence of inhibitor electrodes show Warburg type impedance behaviour in the range of $100 \mathrm{mHz}-100 \mathrm{kHz}$ (Figure 4, inset).

Specific capacitance $\left(C_{\mathrm{sp}}\right)$, double layer capacitance $\left(C_{\mathrm{dl}}\right)$, and phase angle degree were calculated from the impedance measurements for different inhibitor concentration and summarized in Table 2 . The highest specific capacitance value was obtained for $5 \times 10^{-3} \mathrm{M}$ Bis-HSPN.

Basic information on the interaction between the inhibitor and the stainless steel can be provided by the adsorption. The degree of surface coverage $(\theta)$ for different concentrations of DAESPN and Bis-HSPN can be obtained 


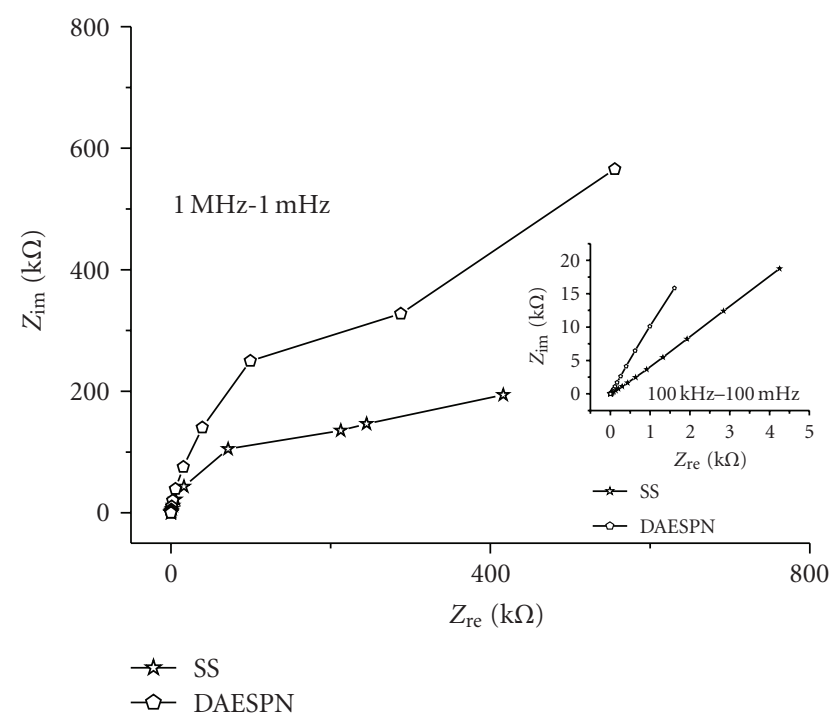

FIGURE 4: Nyquist plot of SS in the presence of $1 \times 10^{-3}$ M DAESPN in $3.0 \mathrm{M} \mathrm{NaCl}$ medium at different frequency range.

from the alternative current impedance study, using the following equation as suggested in the literature [18]:

$$
\theta=\frac{C_{\mathrm{dl}}(\theta=0)-C_{\mathrm{dl},} \theta}{C_{\mathrm{dl}}(\theta=0)-C_{\mathrm{dl}}(\theta=1)},
$$

where $C_{\mathrm{dl}}(\theta=0)$ and $C_{\mathrm{dl}}(\theta=1)$ are the double-layer capacitances (per unit area) of the inhibitor-free and entirely inhibitor covered surfaces, respectively; $C_{\mathrm{dl}}, \theta$ is the composite total double-layer capacitance for any intermediate coverage $\theta$. Higher $\theta$ values were obtained for DAESPN than the values obtained at the same concentrations of Bis-HSPN.

With regard to the Langmuir adsorption isotherm the surface coverage $\theta$ of the inhibitor on the steel surface is related to the concentration $\left(C_{\text {in }}\right)$ of the inhibitor $(M)$ in the bulk of the solution according to the following equation [1921]:

$$
\theta=\frac{K_{\mathrm{ads}} C_{\mathrm{in}}}{1+K_{\mathrm{ads}} C_{\mathrm{in}}}
$$

where $K_{\mathrm{ads}}$ is the equilibrium constant for the adsorption/desorption process. This equation can be rearranged to

$$
\frac{C_{\text {in }}}{\theta}=\frac{1}{K_{\mathrm{ads}}}+C_{\text {in }}
$$

From the intercepts of the straight lines on the $C_{\text {in }} / \theta$-axis, $K_{\text {ads }}$ can be calculated which is related to free energy of adsorption, $\Delta G^{\circ}$ ads as given by

$$
\Delta G_{\mathrm{ads}}^{\circ}=-R T \ln \left(55.5 K_{\mathrm{ads}}\right) .
$$

\section{Conclusion}

Two different types of phthalonitrile were used as inhibitors for SS corrosion in $\mathrm{NaCl}$ medium. Results show that both
TABLe 2: Specific $\left(C_{\mathrm{sp}}\right)$ and double layer capacitance $\left(C_{\mathrm{dl}}\right)$, phase angle and surface coverage values for SS electrode in the presence and absence of different concentrations of DAESPN and Bis-HSPN in $3.0 \mathrm{M} \mathrm{NaCl}$ medium.

\begin{tabular}{lccccc}
\hline & $\begin{array}{c}\text { Concentration } \\
\mathrm{M}\end{array}$ & $\begin{array}{c}C_{\mathrm{sp}}, \\
\mu \mathrm{F}\end{array}$ & $\begin{array}{c}C_{\mathrm{dl}} * 10^{4} \\
\mathrm{~F}\end{array}$ & $\begin{array}{c}\text { Phase } \\
\text { angle }\end{array}$ & $\theta$ \\
\hline Bare & - & 161.6 & 3.50 & 72 & - \\
DAESPN & $1 \times 10^{-3}$ & 112.0 & 4.36 & 80 & 0.43 \\
Bis-HSPN & $1 \times 10^{-3}$ & 95.7 & 3.25 & 78 & 0.13 \\
DAESPN & $5 \times 10^{-3}$ & 132.8 & 5.50 & 82 & 1.00 \\
Bis-HSPN & $5 \times 10^{-3}$ & 137.8 & 3.11 & 70 & 0.20 \\
DAESPN & $5 \times 10^{-4}$ & 123.0 & 5.10 & 80 & 0.80 \\
Bis-HSPN & $5 \times 10^{-4}$ & 101.1 & 3.10 & 75 & 0.20 \\
DAESPN & $1 \times 10^{-4}$ & 95.0 & 2.80 & 74 & 0.35 \\
Bis-HSPN & $1 \times 10^{-4}$ & 87.3 & 2.10 & 74 & 0.70 \\
\hline
\end{tabular}

DAESPN and Bis-HSPN inhibited the corrosion. Increase in concentration results a cathodic shift in corrosion potential indicating inhibitors are effective in cathodic reaction. Impedance measurements suggest that presence of inhibitors protect the electrode. The interaction between the inhibitor and the stainless steel investigated by the adsorption isotherm. Higher $\theta$ values suggest higher surface coverage for DAESPN. Langmuir adsorption isotherm was applied. $K_{\mathrm{ads}}$ and $\Delta G$ values were obtained and found as $4.32 \times$ $10^{-4}, 1.17 \times 10^{-4}$ and $9.2 \mathrm{~kJ}, 12.5 \mathrm{~kJ}$ for DAESPN and BisHSPN, respectively. This results indicates the electrostatic interaction between charged metal surface and charged organic molecules in the bulk of the solution rather than charge sharing or charge transfer between the metal surface and organic molecules.

\section{References}

[1] D. A. Moreno, M. F. L. de Mele, J. R. Ibars Jr., and H. A. Videla, "Influence of microstructure on the electrochemical behavior of type 410 stainless steel in chloride media with inorganic and biogenic sulfide," Corrosion, vol. 47, no. 1, pp. 2-9, 1991.

[2] S. C. Dexter, "Laboratory solutions for studying corrosion of aluminium alloys in seawater," Corrosion, vol. 44, p. 717, 1988.

[3] H. A. Videla, M. F. L. De Mele, and G. Brankevich, “Technical note: assessment of corrosion and microfouling of several metals in polluted seawater," Corrosion, vol. 44, no. 7, pp. 423426, 1988.

[4] A. Y. Aleksanyan, I. I. Reformatskaya, and A. N. Podobaev, "The effect of chloride and sulfate anions on the iron dissolution rate in neutral and nearly neutral media," Protection of Metals, vol. 43, no. 2, pp. 125-128, 2007.

[5] M. Lagrenée, B. Mernari, M. Bouanis, M. Traisnel, and F. Bentiss, "Study of the mechanism and inhibiting efficiency of 3,5-bis(4-methylthiophenyl)-4H-1,2,4-triazole on mild steel corrosion in acidic media," Corrosion Science, vol. 44, no. 3, pp. 573-588, 2002.

[6] F. Bentiss, M. Lagrenee, M. Traisnel, and J. C. Hornez, "The corrosion inhibition of mild steel in acidic media by a new triazole derivative," Corrosion Science, vol. 41, no. 4, pp. 789$803,1999$. 
[7] E. McCafferty, V. Pravdic, and A. C. Zettlemoyer, "Dielectric behaviour of adsorbed water films on alpha- $\mathrm{Fe}_{2} \mathrm{O}_{3}$ surface," Transactions of the Faraday Society, vol. 66, p. 1720, 1970.

[8] F. El-Taib Heakal and S. Haruyama, "Impedance studies of the inhibitive effect of benzotriazole on the corrosion of copper in sodium chloride medium," Corrosion Science, vol. 20, no. 7, pp. 887-898, 1980.

[9] M. Metikos-Hukovic, Z. Grubac, and E. Stupnisek-Lisac, "Organic corrosion inhibitors for aluminum in perchloric acid," Corrosion, vol. 50, no. 2, pp. 146-151, 1994.

[10] U. J. Ekpe, U. J. Ibok, B. I. Ita, O. E. Offiong, and E. E. Ebenso, "Inhibitory action of methyl and phenyl thiosemicarbazone derivatives on the corrosion of mild steel in hydrochloric acid," Materials Chemistry \& Physics, vol. 40, no. 2, pp. 87-93, 1995.

[11] F. Bentiss, M. Lebrini, and M. Lagrenée, "Thermodynamic characterization of metal dissolution and inhibitor adsorption processes in mild steel/2,5-bis(n-thienyl)-1,3,4-thiadiazoles/ hydrochloric acid system," Corrosion Science, vol. 47, no. 12, pp. 2915-2931, 2005.

[12] F. Chaouket, A. Sghiri, A. BenBachir, and A. Frignani, "Corrosion inhibitors," in Proceedings of the 8th European Symposium on Corrosion Inhibitors, p. 1031, September 1995.

[13] P. Premkumar, K. Kannan, and M. Natesan, "Effect of menthol coated craft paper on corrosion of copper in $\mathrm{HCl}$ environment," Bulletin of Materials Science, vol. 33, no. 3, pp. 307-311, 2010.

[14] D. M. Brasher and A. H. Kingsburg, "Electrical measurements in the study of immersed paint coatings on metal. I. Comparison between capacitance and gravimetric methods of estimating water-uptake," Journal of Applied Chemistry, vol. 4, no. 2, pp. 62-72, 1954.

[15] S. Y. Zhang, W. F. Zhou, X. W. Luo, and S. J. Li, "Evaluation of thin defect-free epoxy coatings using electrochemical impedance spectroscopy," Journal of Applied Electrochemistry, vol. 28, no. 11, pp. 1277-1281, 1998.

[16] T. Szauer and A. Brandt, "On the role of fatty acid in adsorption and corrosion inhibition of iron by amine-fatty acid salts in acidic solution," Electrochimica Acta, vol. 26, no. 9, pp. 1219-1224, 1981.

[17] M. M. Osman, A. M. A. Omar, and A. M. Al-Sabagh, "Corrosion inhibition of benzyl triethanol ammonium chloride and its ethoxylate on steel in sulphuric acid solution," Materials Chemistry and Physics, vol. 50, no. 3, pp. 271-274, 1997.

[18] O. Benali, L. Larabi, B. Tabti, and Y. Harek, "Influence of 1-methyl 2-mercapto imidazole on corrosion inhibition of carbon steel in $0.5 \mathrm{M}$ HSO," Anti-Corrosion Methods and Materials, vol. 52, no. 5, pp. 280-285, 2005.

[19] H. Keleş, M. Keleş, I. Dehri, and O. Serindağ, "Adsorption and inhibitive properties of aminobiphenyl and its Schiff base on mild steel corrosion in $0.5 \mathrm{M} \mathrm{HCl}$ medium," Colloids and Surfaces A, vol. 320, no. 1-3, pp. 138-145, 2008.

[20] G. Moretti, G. Quartarone, A. Tassan, and A. Zingales, "5amino- and 5-chloro-indole as mild steel corrosion inhibitors in in sulphuric acid," Electrochimica Acta, vol. 41, no. 13, pp. 1971-1980, 1996.

[21] A. K. Singh and M. A. Quraishi, "Investigation of adsorption of isoniazid derivatives at mild steel/hydrochloric acid interface: electrochemical and weight loss methods," Materials Chemistry and Physics, vol. 123, no. 2-3, pp. 666-677, 2010. 


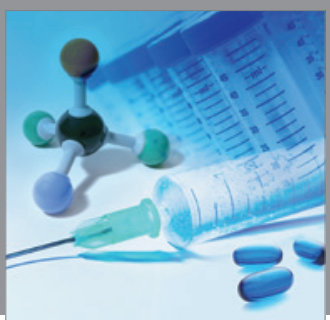

International Journal of

Medicinal Chemistry

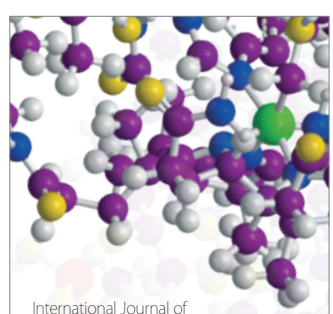

Carbohydrate Chemistry

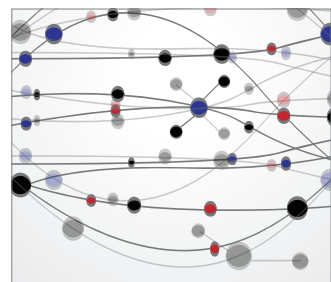

The Scientific World Journal
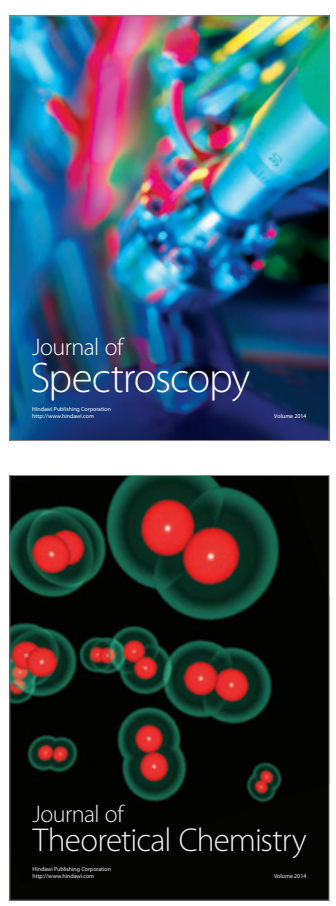
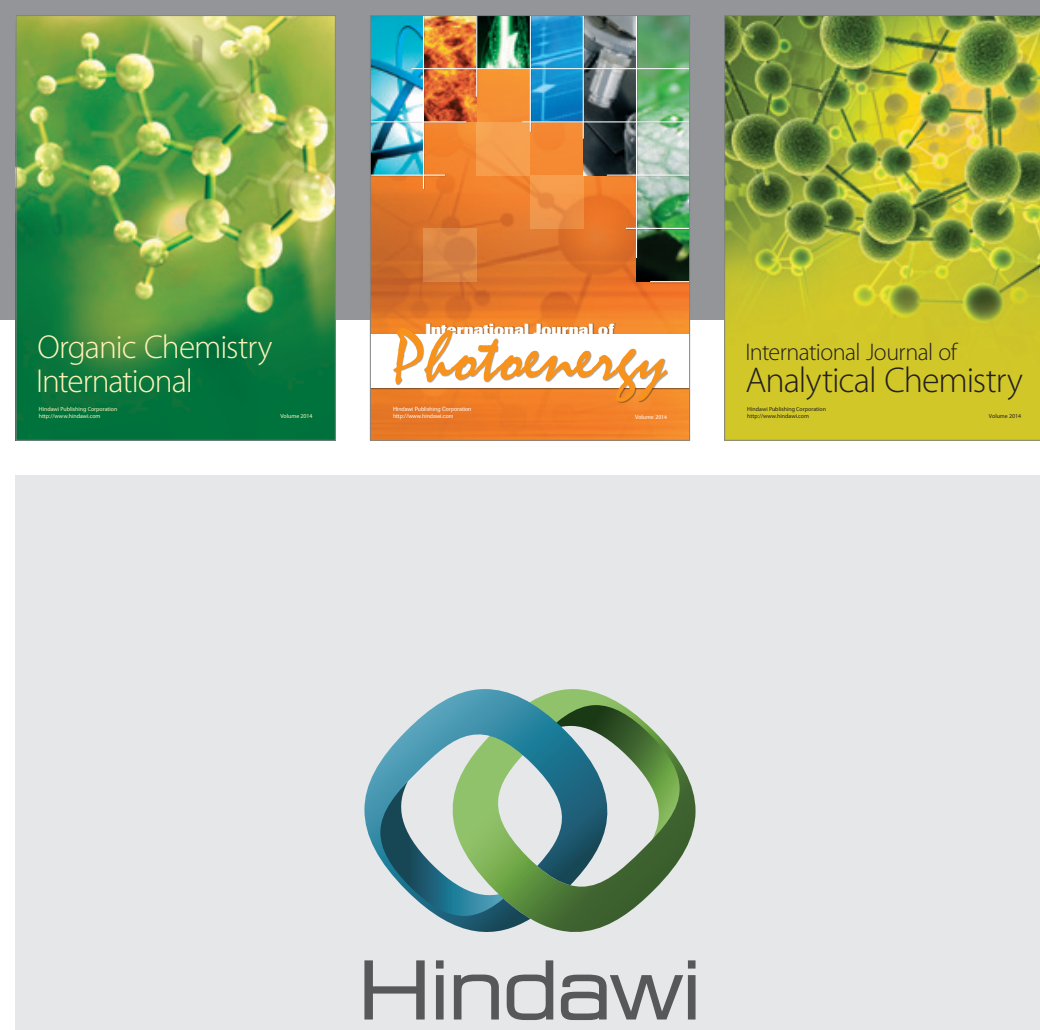

Submit your manuscripts at

http://www.hindawi.com
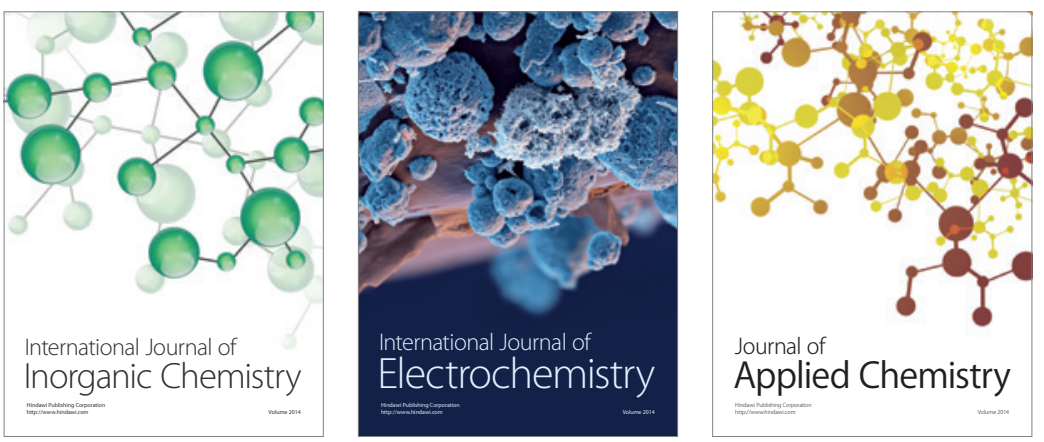

Journal of

Applied Chemistry
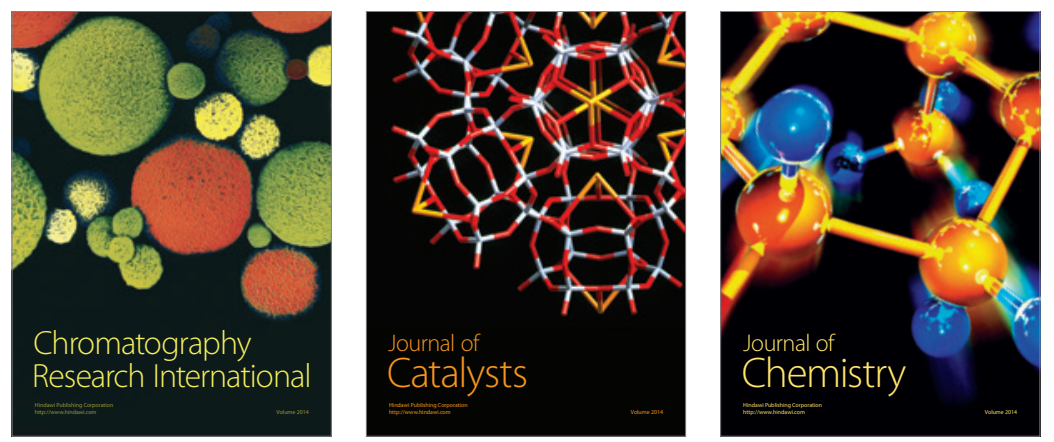
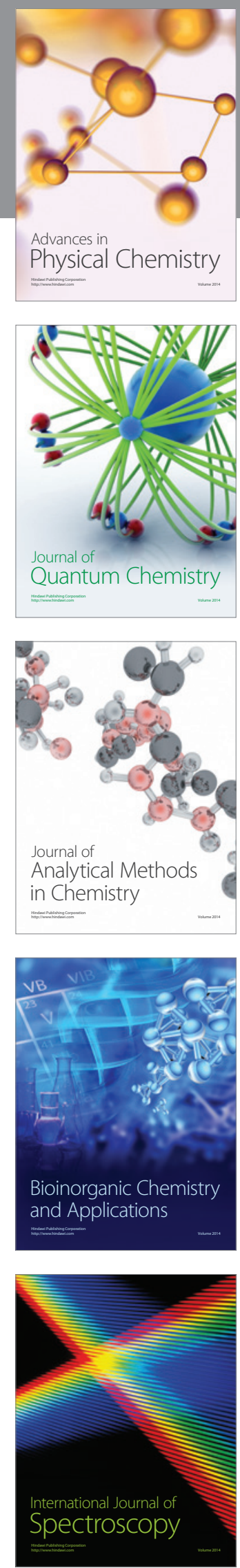